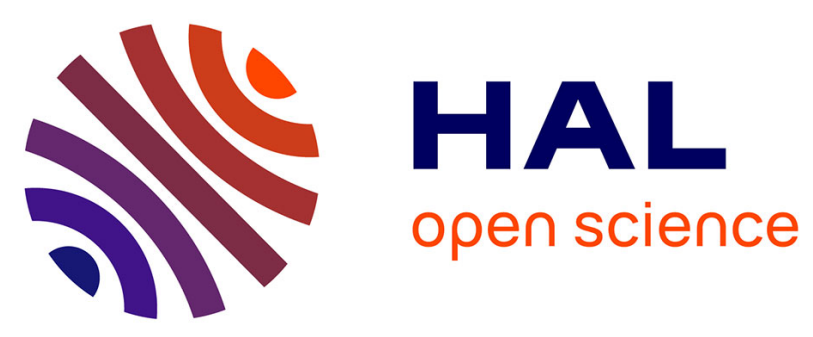

\title{
Host preferences and circadian rhythm of Culicoides (Diptera: Ceratopogonidae), vectors of African horse sickness and bluetongue viruses in Senegal
}

Moussa Fall, Assane G. Fall, Momar T. Seck, Jérémy Bouyer, Maryam Diarra, Renaud Lancelot, Geoffrey Gimonneau, Claire Garros, Mame T. Bakhoum, Ousmane Faye, et al.

\section{To cite this version:}

Moussa Fall, Assane G. Fall, Momar T. Seck, Jérémy Bouyer, Maryam Diarra, et al.. Host preferences and circadian rhythm of Culicoides (Diptera: Ceratopogonidae), vectors of African horse sickness and bluetongue viruses in Senegal. Acta Tropica, 2015, 149, pp.239-245. 10.1016/j.actatropica.2015.06.012 . hal-02641485

\section{HAL Id: hal-02641485 \\ https: / hal.inrae.fr/hal-02641485}

Submitted on 28 May 2020

HAL is a multi-disciplinary open access archive for the deposit and dissemination of scientific research documents, whether they are published or not. The documents may come from teaching and research institutions in France or abroad, or from public or private research centers.
L'archive ouverte pluridisciplinaire HAL, est destinée au dépôt et à la diffusion de documents scientifiques de niveau recherche, publiés ou non, émanant des établissements d'enseignement et de recherche français ou étrangers, des laboratoires publics ou privés. 


\section{Accepted Manuscript}

Title: Host preferences and circadian rhythm of Culicoides (Diptera: Ceratopogonidae), vectors of African horse sickness and bluetongue viruses in Senegal

Author: Moussa Fall Assane G. Fall Momar T. Seck Jérémy Bouyer Maryam Diarra Renaud Lancelot Geoffrey

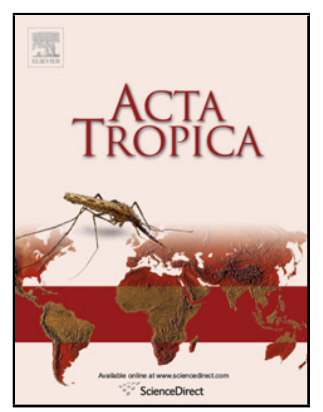

Gimonneau Claire Garros Mame T. Bakhoum Ousmane Faye Thierry Baldet Thomas Balenghien

\begin{tabular}{|c|c|}
\hline PII: & S0001-706X(15)30032-2 \\
\hline DOI: & http://dx.doi.org/doi:10.1016/j.actatropica.2015.06.012 \\
\hline Reference: & ACTROP 3654 \\
\hline To appear in: & Acta Tropica \\
\hline Received date: & $5-3-2015$ \\
\hline Revised date: & $10-6-2015$ \\
\hline Accepted date: & $12-6-2015$ \\
\hline
\end{tabular}

Please cite this article as: Fall, Moussa, Fall, Assane G., Seck, Momar T., Bouyer, Jérémy, Diarra, Maryam, Lancelot, Renaud, Gimonneau, Geoffrey, Garros, Claire, Bakhoum, Mame T., Faye, Ousmane, Baldet, Thierry, Balenghien, Thomas, Host preferences and circadian rhythm of Culicoides (Diptera: Ceratopogonidae), vectors of African horse sickness and bluetongue viruses in Senegal.Acta Tropica http://dx.doi.org/10.1016/j.actatropica.2015.06.012

This is a PDF file of an unedited manuscript that has been accepted for publication. As a service to our customers we are providing this early version of the manuscript. The manuscript will undergo copyediting, typesetting, and review of the resulting proof before it is published in its final form. Please note that during the production process errors may be discovered which could affect the content, and all legal disclaimers that apply to the journal pertain. 


\section{Host preferences and circadian rhythm of Culicoides (Diptera:}

\section{Ceratopogonidae), vectors of African horse sickness and bluetongue viruses in Senegal}

Moussa Fall ${ }^{1,3}$, Assane G. Fall ${ }^{1}$, Momar T. Seck ${ }^{1}$, Jérémy Bouyer ${ }^{1,2,45,6}$, Maryam Diarra ${ }^{1}$, Renaud Lancelot ${ }^{2}$, Geoffrey Gimonneau ${ }^{1,2}$, Claire Garros ${ }^{2}$, Mame T. Bakhoum ${ }^{1}$, Ousmane Faye $^{3}$, Thierry Baldet ${ }^{2}$, Thomas Balenghien ${ }^{2}$

${ }^{1}$ Institut Sénégalais de Recherches Agricoles, Laboratoire National de l'Elevage et de Recherches Vétérinaires, BP 2057, Dakar - Hann, Sénégal.

${ }^{2}$ Centre de Coopération Internationale en Recherche Agronomique pour le Développement, Unité Mixte de Recherche Contrôle des Maladies Animales Exotiques et Emergentes, Campus International de Baillarguet, F34398, Montpellier, France

${ }^{3}$ Faculté des Sciences et Techniques, Département de Biologie Animale, Cheikh Anta Diop University, Dakar BP 5005, Senegal

${ }^{4}$ Institut National de la Recherche Agronomique (INRA), Unité Mixte de Recherche 1309

${ }^{5}$ Pan-African Tsetse and Trypanosomosis Eradication Campaign, 01 BP 1087, BoboDioulasso, Burkina Faso

${ }^{6}$ Centre de Coopération Internationale en Recherche Agronomique pour le Développement (CIRAD), Unité Mixte de Recherche 'Interactions hôtes-vecteurs-parasites-environnement dans les maladies tropicales négligées dues aux trypanosomatidés', 34398 Montpellier, France

Correspondingauthor.

Moussa Fall, ISRA-LNERV, Route du Front de Terre, BP 2057, Dakar-Hann, Sénégal.

Tel.: + 221779532645

Fax: +221338323679

E-mail: moussafall08@yahoo.fr

Highlights

- We described host-seeking activity of C.oxystoma and C.imicola in Senegal

- We compared host preferences of these Culicoides for horse and sheep

- We ed the nuisance associated with Lasiohelaesp for animals

- Midges preferred horse compared to sheep and are mainly crepuscular

\section{Abstract}


African horse sickness- and bluetongue virus are orbiviruses transmitted by Culicoides biting midges (Diptera: Ceratopogonidae) to horses and to ruminants respectively. Since the last epizootic outbreak of African horse sickness in 2007 in Senegal, extensive investigations have been undertaken to improve our knowledge on Culicoides species involved locally in the transmission of the virus. The purpose of this study was to compare and quantify the host preferences of potential vectors of these orbiviruses on horse and sheep and to study their circadian rhythm. We found that Culicoides oxystoma and species of the sub-genus Avaritia (C.imicola, C. bolitinos and C. pseudopallidipennis) had a preference for horse when compared to sheep (the predicted ratio between horse and sheep was 80 for C. oxystoma and 26 for C. imicola), and were mostly crepuscular: C. oxystoma had continuous activity throughout the diel with peaks in numbers collected after sunrise and sunset, while $C$. imicola was mostly nocturnal with peak after sunset. Unexpectedly, species of the subgenus Lasiohelea was also collected during this study. This diurnal biting species was a nuisance pest for both animal species used as bait.

Key words: Culicoides, Orbivirus transmission, host-feeding pattern, diel host-seeking activity, Thiès (Senegal)

\section{Introduction}

African horse sickness (AHS) and bluetongue (BT) are endemic diseases in West Africa; caused by Orbiviruses (Reoviridae) transmitted by small hematophagous insects of the genus Culicoides (Diptera: Ceratopogonidae). In southern Africa, Culicoides imicola Kieffer and Culicoides bolitinos Meiswinkel are proven vectors of African horse sickness virus (AHSV) (Venter et al., 1999; Venter et al., 2000; Meiswinkel \& Paweska, 2003) and of bluetongue virus (BTV) (Rawlings et al., 1997; Venter et al., 2000; Mellor \& Hamblin, 2004). Little is known about the biology and ecology of Culicoides species in West Africa, in particular those involved in the transmission of AHS and BT, which impedes the development of efficient vector control methods.

Culicoides oxystoma Kieffer was detected for the first time in Senegal in 2011 (Bakhoum et al., 2013). This species is abundant in light-traps in the Niayes area(Diarra et al., 2014), a region particularly affected by the previous epizootic outbreak of AHS in 2007; it is also aggressive towards horses (Fall et al., 2015). Furthermore, these studies collected up to 41 
Culicoides species (this increased the number of described Culicoides species found in Senegal from 34 to 53) and highlighted that Culicoides kingi Austen reaches abundances on horse equivalent to those of $C$. imicola. It may be that $C$. oxystoma and $C$. kingi also contribute to the transmission of the AHSV in Senegal, and more broadly in West Africa (Fall et al., 2015). Culicoides oxystoma has been reported as a putative vector for BTV in northern India (Prasad et al., 1999), as involved in the transmission of bovine arboviruses such as Akabane virus in Japan (Kurogi et al., 1987; Yanase et al., 2005) and is suspected of transmitting the epizootic haemorrhagic disease virus (EHDV) in Israel (Morag et al., 2012). Culicoides kingi has been found in the field to be infected by EHDV in Sudan (Mellor et al., 1984).

Outside of South Africa, little research has been conducted on the biology and ecology of the African species of the genus Culicoides. The only in-depth investigations were conducted in Cameroon (Nicholas, 1953), Gabon (Auriault, 1977) and Congo (Vattier-Bernard et al., 1986; Itoua et al., 1987) and primarily related to Culicoides grahamii Austen. This species is anthropophilic and its peak feeding activity occurs at sunrise and sunset, causing a nuisance to humans in some areas and during abundance seasons. However, most Culicoides species studied in Central Africa are zoo-anthropophilic in their feeding behaviour, e.g. Culicoides kumbaensis Callot, Kremer, Mouchet and Bach, Culicoides fulvithorax Austen, Culicoides dubitatus Kremer, Rebholtz-Hirtzel and Delécolle and Culicoides trifasciellus Goetghebuer (Itoua et al., 1987). Outside southern Africa, the only African species of veterinary significance studied so far are C. kingi in Sudan which displays two biting peaks: one after sunrise and the other close to sunset (El Sinnary et al., 1985).

This illustrates how fragmentary current data about the life history and ecology of Culicoides is in Africa. The present study describes host preferences, as key elements in the transmission of arboviruses, of Culicoides that are potential vectors of the AHSV and BTV in Senegal by comparing their attraction to horse and sheep and determining their circadian rhythm.

\section{Materials and methods}

\section{1) Study Area}

The study was conducted at the Thiès national stud farm between 29 August and 28 September, 2013 in the middle of the rain season. This stud farm was located in a forested 
area. This season was selected as optimal for Culicoides abundance, and this site was selected because $C$. imicola and $C$. oxystoma were both abundant (Diarra et al., 2014). The city of Thiès is in the Niayes area; it is characterised by depressions between dunes that flooded during the rainy season. These depressions are located from Dakar in the south to the Senegal River Delta in the north. This is an area where commercial garden crops and fruit are intensively grown. Dairy and poultry farms are also found there together with a number of riding centres that accommodate purebred horses. Rainfall rarely exceeds $500 \mathrm{~mm} / \mathrm{year}$ with a rainy season ranging from July to October. Ocean vicinity is conducive to a high relative moisture rate ranging from $90 \%$ to $15 \%$, depending on the distance from the sea and time of year.

\section{2) Host-baited trap collections}

We compared two hosts on two sites using a Latin-square design. One horse and two sheep were used. No insecticide was applied on animals the year before the start of the experiment. The horse was across-bred English yearling weighing between 110 and $120 \mathrm{~kg}$. The sheep were two ewes of a local breed weighing between 25 and $30 \mathrm{~kg}$ each. The baited traps used were identical to that used by Fall et al. (2015). The animal-baited trap consists of a net box $(3.5 \mathrm{~m} \times 2.5 \mathrm{~m} \times 2.5 \mathrm{~m}$, with mesh of $1.5 \mathrm{~mm} \times 0.3 \mathrm{~mm})$ with an open space of $15 \mathrm{~cm}$ fromthe ground allowing Culicoides to enter, to engorge or not on animal, and avoiding the escape of trapped midges. The traps were placed at two locations separated by a distance of $150 \mathrm{~m}$ (without visual contact between them) to minimise between-trap interactions. Other horses were present in vicinity of the stud farm for pasturage and a cattle herd was grazing at a distance of more than $1,000 \mathrm{~m}$.

Collections were conducted in three sessions. During each session, midges were collected every three hours over two periods of 24 hours - midges trapped inside the tents were collected for 10-15 min using an electric vacuum cleaner.Each 24-h period was spread over two consecutive days, stretching from midday (day 1) to midday (day 2). The two 24-h periods were separated by a 3-h interval to allow the switch of animals between the two locations. Thus, horse and sheep were exposed during 24 × 2 × $3=144$ hours each.

\section{3) Culicoides identification}


The insects collected were killed by low temperature and identified. Morphological identification of Culicoides species relied on an examination of wing patterns under a stereomicroscope(Zeiss, Stemi DV4) using the morphological keys for the Afrotropical region (Boorman \& Dipeolu, 1979; Boorman, 1989; Meiswinkel, 1989; Glick, 1990; Meiswinkel, 1991; Cornet \& Brunhes, 1994). When needed, specimens were dissected and slide-mounted in accordance with the Wirth and Marston (1968) technique. Culicoides were counted by species and sex, and females were categorized as nulliparous or parous (Dyce, 1969), engorged or unengorged, and gravid or not. The specimens were placed in Eppendorf tubes and stored in $90 \%$ alcohol.

\section{4) Statistical analysis}

Abundances on respective hosts were compared by species using the raw data and data adjusted for host weight. Engorgement rates were computed by dividing the number of engorged females by the total number of females collected.

Unadjusted abundance of Culicoides species was modelled using a Poisson mixed-effect model fitted with a method providing an adaptive Gauss-Hermite approximation to the maximized log-likelihood. We used the trapping day (1 to 6) as a random effect, and the location and the host (horse, sheep) as fixed effects. Selection of effects in the abundance model was based on a likelihood ratio test, the confidence intervals for parameters in the fitted model, and the Akaike information criterion (AIC). The procedure proposed by Nakagawa and Schielzeth (2013) was used as an overall test for goodness of fit.

All data analyses were performed using R statistical packages(R_Core_Team, 2014).

\section{Results}

Collections were carried out during the rainfall season. Weather was cloudy during the two first collection sessions and sunny during the last session. Temperatures varied from 23.2 to $32.8^{\circ} \mathrm{C}$ the first collection session, from 26.4 to $34.8^{\circ} \mathrm{C}$ the second session, and from 25.2 to $33.6^{\circ} \mathrm{C}$ the third session and humidity varied from 55.1 to $90.6 \%$, from 49.3 to $84.6 \%$ and from 47.0 to $85.6 \%$ for the three sessions. Intra-session amplitudes of both temperature and humidity were higher (about $9^{\circ} \mathrm{C}$ and $37 \%$ ) than inter-session amplitudes $\left(1-3^{\circ} \mathrm{C}\right.$ and $\left.1-9 \%\right)$.

\section{Host preference}

A total of 1,259 Culicoides specimens were collected, of which 54 were males. In total, 1,215 Culicoides were collected in the horse-baited trap, i.e. $96.5 \%$ of overall collections, vs. 44 in 
the sheep-baited trap, i.e. 3.5\% (Table 1). We identified 11 different species, all of which were found in the horse-baited trap, while only 8 were found in the sheep-baited trap. Culicoides oxystoma, the only representative species of the Schultzei group, was predominant in the collections, with 928 specimens (73.7\%). The medium-abundance species belonged to the Imicola group, namely C. imicola with 214 specimens (16.9\%), C. bolitinos with 55 specimens (4.3\%) and Culicoides pseudopallidipennis Clastrier with 34 specimens $(2.7 \%)$. Taken together, these 4 species accounted for $97.8 \%$ of the Culicoides collected (Table 1). The engorgement rate for these species ranged from 40 to $50 \%$ on the horse and was $20 \%$ on sheep for C. oxystoma (Table 1). The other species - C. trifasciellus, Culicoides translucens Khamala and Kettle, Culicoides nivosus De Meillon, Culicoides nigripennis Carter, Ingram and Macfie and Culicoides moreli Clastrier were uncommon. Finally, Culicoides accraensis Carter, Ingram and Macfieand Culicoides leucostictus Kieffer were not attracted by the horse and sheep baits and their collection was incidental since only gravid females or males were identified. The Culicoides population was relatively young with a nulliparous rate of $70 \%$.

Overall, Culicoides numbers were fairly balanced between sites (593 in one site and 600 in the other). The number of females caught varied significantly between trapping sessions. Both the raw and the host weight-adjusted figures were always much greater for the horse than for the sheep-baited trap for C. oxystoma, C. imicola, C. bolitinos and C. pseudopallidipennis (Figure 1); from 96 to $98 \%$ of females were collected on this host (Table 1).

To predict the abundance of $C$. oxystoma females, we selected the full model with the site and the host as the fixed effects, and the trapping day as the random effect. The conditional $R^{2}$ (percentage of variance explained by both fixed and random effects) was very high (99.6\%), whereas the marginal $R^{2}$ (percentage of variance explained by fixed effects) was high (marginal $R^{2}=64.6 \%$ ), and mainly $(96.0 \%)$ explained by the host effect. For the fixed effects, the model predicted a ratio of 80 between females collected on the horse and those collected on the sheep (the horse weighing twice as much as the ewes) and a ratio of 2.5 between the two sites. To predict the abundance of $C$. imicola females, we selected the full model. The conditional $\mathrm{R}^{2}$ was very high (97.0), whereas the marginal $\mathrm{R}^{2}$ was high (63.8), and mainly (94.2\%) explained by the host effect. For the fixed effect, this model predicted a ratio of 26 between females collected on the horse and those collected on the sheep and a ratio of 2.2 between the two sites. 

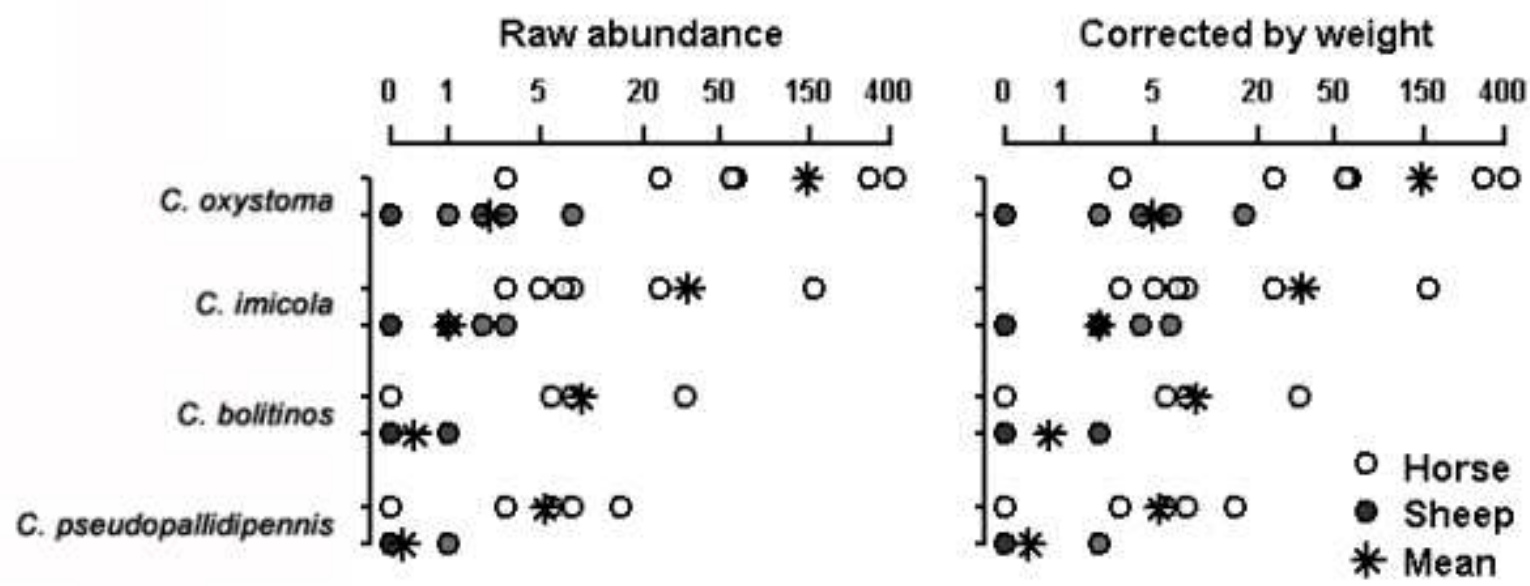

Figure 1: Raw abundance and host weight-adjusted abundance of Culicoides oxystoma, Culicoides imicola, Culicoides bolitinos, and Culicoides pseudopallidipennis females collected on each host. Both plots look quite similar as weight-correction (which is limited as two sheep were used against one horse) was applied on the numbers of Culicoides collected on sheep, which were always low.

Table 1. Number of Culicoides collected during the 6 trapping days on horse and sheep baits

\begin{tabular}{|c|c|c|c|c|c|c|c|c|c|c|c|c|c|}
\hline \multirow{2}{*}{ Culicoides species } & \multicolumn{5}{|l|}{ Total } & \multicolumn{7}{|c|}{ Horse-baited trap } & Sheep-bai \\
\hline & Rank & $(\mathbf{C} \%)$ & $\mathbf{F}$ & (P) & $\mathbf{M}$ & $F$ & bf $F$ & (bf R) & $\mathbf{N}$ & $\mathbf{P}$ & $\mathbf{G}$ & $\mathbf{M}$ & $F$ \\
\hline C. oxystoma & 1 & 73.7 & 881 & 35.8 & 47 & 867 & 381 & 43.9 & 308 & 176 & 2 & 36 & $\overline{14}$ \\
\hline C. imicola & 2 & 90.7 & 212 & 12.8 & 2 & 206 & 99 & 48.0 & 91 & 14 & 2 & 1 & 6 \\
\hline C. bolitinos & 3 & 95.1 & 55 & 16.1 & 0 & 53 & 22 & 41.5 & 26 & 4 & 1 & 0 & 2 \\
\hline C. pseudopallidipennis & 4 & 97.8 & 33 & 5.6 & 1 & 32 & 14 & 43.8 & 17 & 1 & 0 & 0 & 1 \\
\hline C. trifasciellus & 5 & 98.7 & 11 & - & 0 & 11 & 3 & - & 6 & 2 & 1 & 0 & 0 \\
\hline C. translucens & 6 & 99.1 & 4 & - & 1 & 1 & 0 & - & 0 & 0 & 1 & 1 & 3 \\
\hline C. nivosus & 7 & 99.4 & 3 & - & 1 & 0 & 0 & - & 0 & 0 & 0 & 1 & 3 \\
\hline C. nigripennis & 8 & 99.7 & 3 & - & 1 & 2 & 0 & - & 0 & 2 & 0 & 1 & 1 \\
\hline C. accraensis & 9 & 99.9 & 2 & - & 0 & 1 & 0 & - & 0 & 0 & 1 & 0 & 1 \\
\hline C. moreli & 10 & 100.0 & 0 & - & 1 & 1 & 0 & - & 0 & 1 & 0 & 0 & 0 \\
\hline C. leucostictus & 11 & 100.0 & 1 & - & 0 & 0 & 0 & - & 0 & 0 & 0 & 1 & 0 \\
\hline TOTAL & & & 1,205 & 30.4 & 54 & 1,174 & 519 & 44.2 & 448 & 200 & 7 & 41 & 31 \\
\hline
\end{tabular}

$(\mathrm{C} \%)$ : cumulative percentages of abundance; $\mathrm{F}$ : number of females; $(\mathrm{P})$ : parous rate; $\mathrm{M}$ : number of males; bfF: number of engorged females; (bfR): engorgement percentage; $N$ : number of nulliparous females; P: number of parous females; G: number of gravid females.

\section{Circadian rhythms}

Figure 2 shows the overall abundance of C. oxystoma, C. imicola, C. bolitinos, and C. pseudopallidipennis females over the diel regardless of host. For each species, observed abundances in each trapping session were correlated for nulliparous, parous, gravid and 
engorged females, thus suggesting that there was no activity difference related to time of day associated with differences in the physiological status of females. Culicoides oxystoma was collected at all times, with activity peaks immediately after sunrise, and immediately after sunset. Culicoides imicola was nocturnal and its activity peaked just after sunset. The activity of $C$. bolitinos and C.pseudopallidipennis peaked just after sunset and sunrise but the low numbers collected renders it difficult to validate this result.

C. oxystoma

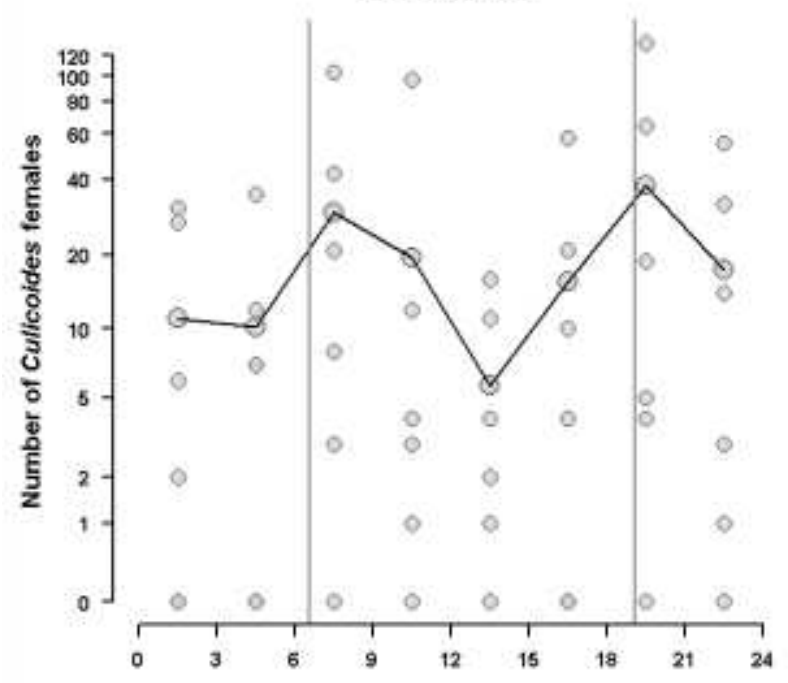

C. bolitinos

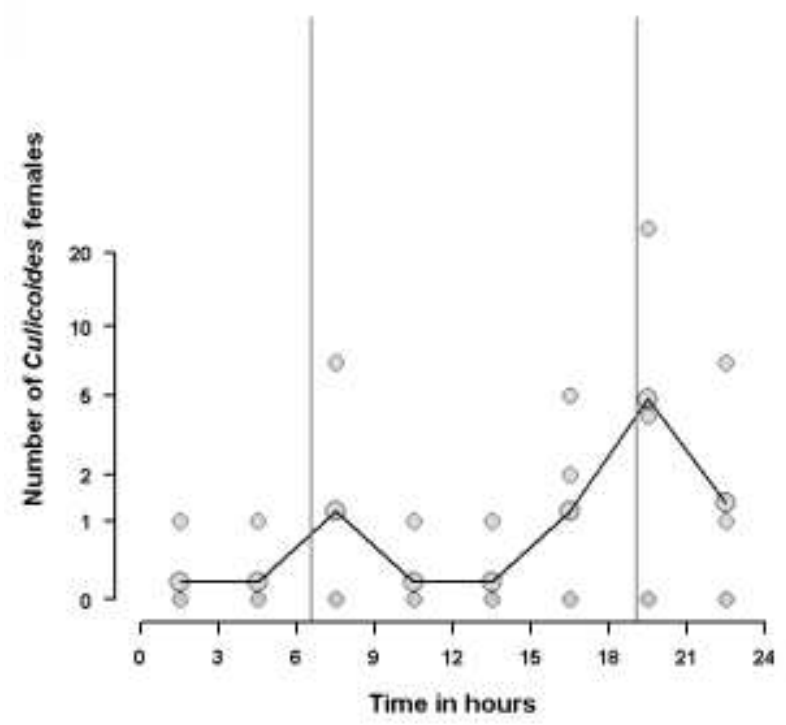

C. imicola

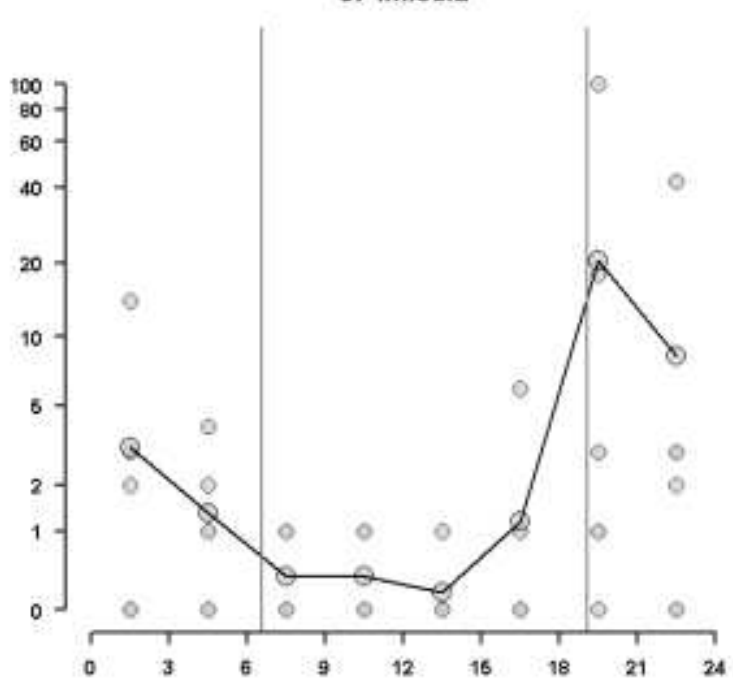

c. pseudopallidipennis

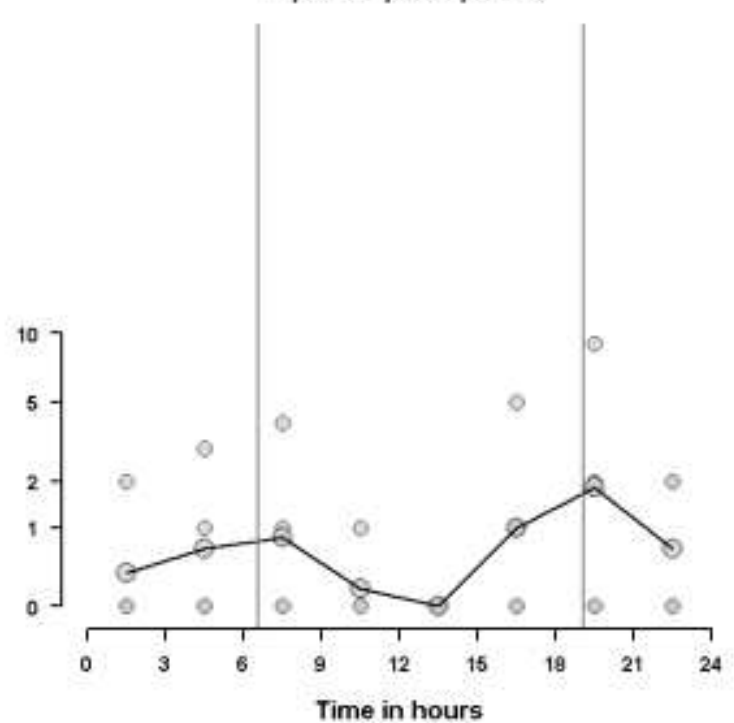

Figure 2: Circadian activity of female Culicoides oxystoma, C. imicola, C. bolitinos, and C. pseudopallidipennis, collected in host-baited traps regardless of the host. The black, broken line represents the average of observations. The vertical grey lines illustrate the time of sunrise and sunset.

Additionally, we identified another Ceratopogonidae species of the Forcipomyia genus and of the Lasiohelae sub-genus that was remarkably aggressive towards the hosts, particularly the 
horse. No male was collected and we were unable to identify the specimens to the species level. A total of 735 specimens were collected, 644 of which were found on the horse (87.6\%), with an engorgement rate of $80.2 \%$, as compared with 91 specimens collected on the sheep (12.4\%), with an engorgement rate of $70.3 \%$. This species of the Lasiohelea subgenus was markedly diurnal and its peak of activity is the pre-sunset period (Figure 3).

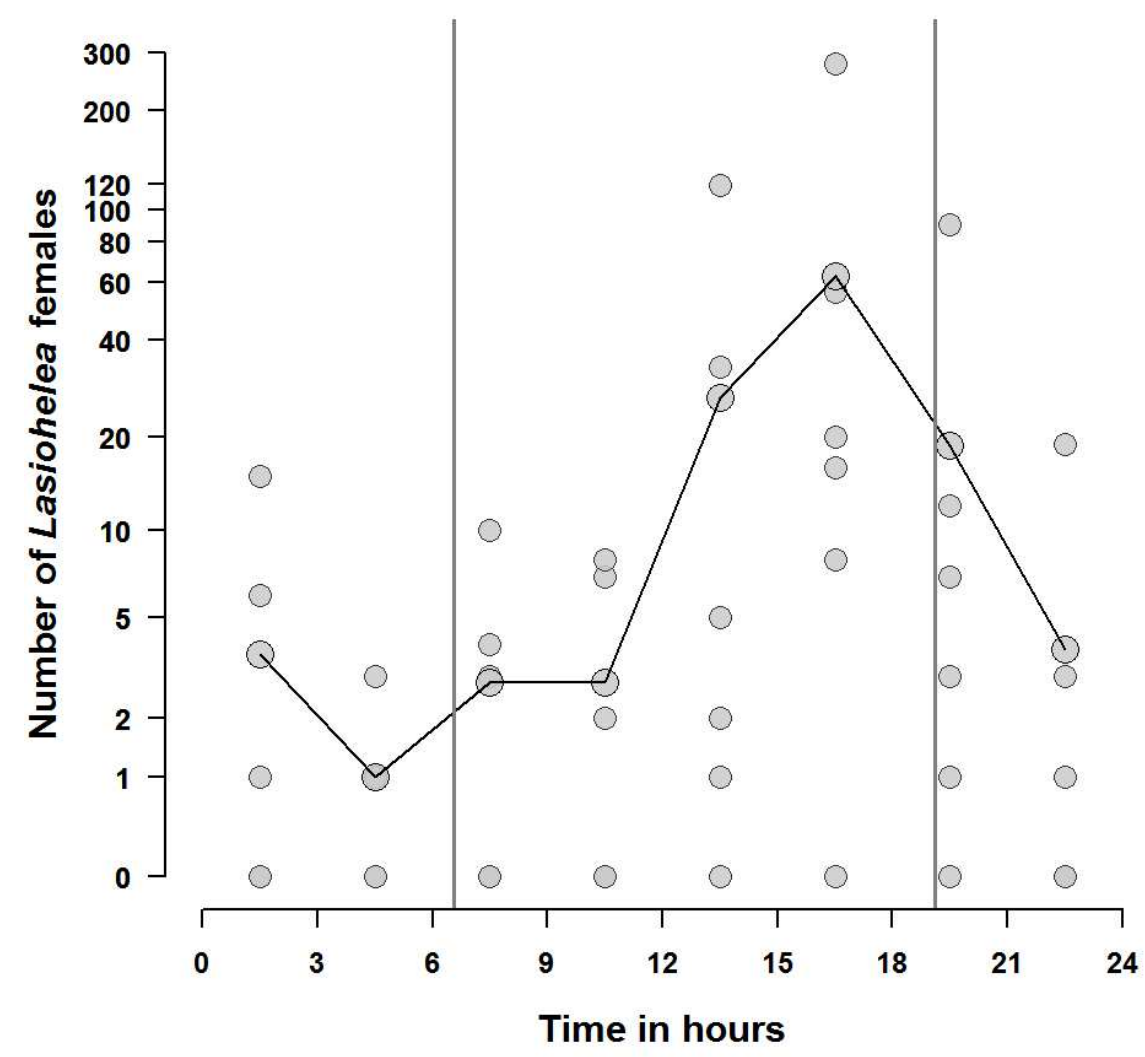

Figure 3: Circadian activity of females belonging to the unknown of the Lasiohelea subgenus, i.e. overall number of females collected in each catch regardless of host. The black, broken line represents the mean of the observations. The vertical grey lines illustrate time of sunrise and sunset.

\section{Discussion}

The predominance of $C$. oxystoma and $C$. imicola in UV-light traps and horse-baited traps has previously been reported in the region (Diarra et al., 2014; Fall et al., 2015).This study showed a host preference of $C$. oxystoma and Culicoides species from the Avaritia sub-genus for horse as compared to sheep. Similar host preference for horse was found by Viennet et 
al.(2012) for Culicoides species of veterinary significance using host-baited traps in the Palearctic region. The authors did not however reach the conclusion that horse were more attractive than other hosts, or that there was a non-linear relationship between weight and attractiveness (the horse being by far the largest host). In our study, the limited difference in weight between the horse and the sheep suggested that this difference in abundance was connected with greater attractiveness of horse for the 4 most abundant Culicoides species collected.

The number of midges collected varied between days. The numbers collected in baited traps depended not only on factors inherent to the host but also on weather conditions. Indeed, Cornet (1969) and Walker (1977) reported that as soon as night temperatures were somewhat higher in the Afro-tropical region, the number of specimens collected by light trap increased. Moreover, it is classically reported that catches in light trap or on human bait were generally higher on moonless nights in Sub-Saharan Africa (Cornet, 1969; Auriault, 1979; Itoua et al., 1987) and in other regions (Mellor et al., 2000). Host attractiveness to haematophagous insects can be dependent on the size of the host, its body temperature, the carbon dioxide (CO2) its other specific odours or its colour, as it has been highlighted by many studies conducted on mosquitoes (Dow et al., 1957; Edman et al., 1974; Lardeux et al., 2007; Takken \& Verhulst, 2013). Wind can also disrupt the odour flows emanating from the host or interfere with insect activity: Almost all activity was suppressed at wind speeds greater than three $\mathrm{m} / \mathrm{s}$ for $C$. imicola in Kenya (Walker, 1977). Host colour does not seem to have any influence on engorgement rate of Culicoides sanguisuga Coquillett and Culicoides guttipennis Coquillett (Humphreys \& Turner, 1973). Carbon dioxide attracted specimens of the Variipennis complex in northern America (Nelson, 1965; Mullens, 1995) and Culicoides impunctatus Goetghebuer in Scotland (Bhasin et al., 2001). Also, greater host size, corresponding to higher quantity of carbon dioxide released by the host, resulted in greater host attractiveness for Culicoides to hosts (Humphreys \& Turner, 1973; Tanner \& Turner, 1974; Raich et al., 1997).

The predominance of $C$. oxystoma in the horse-baited trap in the Niayes region was in line with observations made by Fall et al.(2015) using the same trap. Interestingly, Culicoides subschultzei Cornet and Brunhes was consistently collected in very small numbers in studies on Culicoides associated with livestock collected by light trap in southern Africa (Venter et al., 1996; Mushi et al., 1998) and in western Africa (our study) whereas this species was previously considered using light traps as highly abundant in the south and eastern Africa 
region (Cornet \& Brunhes, 1994). This reputation was however based on taxonomic investigations in forested areas, which might explain this apparent mismatch. Scheffer et al.(2012) showed there were no C. subschultzei among the insects collected on horses by direct suction in South Africa. Culicoides oxystoma is regarded as abundant in light trap collections in the vicinity of livestock in areas where it is present (Oem et al., 2013; Satheesha et al., 2014). Following the detection of C. oxystoma in the Afro-tropical region (Bakhoum et al., 2013) and due to the taxonomic imbroglio pertaining to the Schultzei group (Cornet \& Brunhes, 1994), the status of the species in this group needs to be clarified. Further research is needed on host preferences in different ecosystems and different seasons, including in other African countries, to supplement the observations made in this study.

The night-time host seeking activity of $C$. imicola recorded in our study matched previous findings (Barnard, 1997; Meiswinkel et al., 2000). As this species is exophilic, enter horses into closed holdings during the night might protect them from $C$. imicola bites and then against AHSV transmission. Culicoides bolitinos and C.pseudopallidipennis are also nocturnal.Although $C$. bolitinos does not seem to use horse manure as a larval developing site, it is considered as a vector of AHSV. The presence of cattle near horses may increase the numbers of $C$. bolitinos, and the risk of AHSV being transmitted, in a given area.

Culicoides trifasciellus was only collected in the horse-baited trap. Due to the low numbers collected, no firm conclusions can be drawn as to its feeding patterns. However, this species is undoubtedly zoo-anthropophilic (Itoua et al., 1987). Its taxonomic status is uncertain as for other species such as $C$. brosseti and $C$. dubitatus, the male specimens of $C$. dubitatus being highly characteristic (Kremer et al., 1975). Added to this, no taxonomic keys based on morphological characters are available for these species. It should also be noted that only one C. nivosus specimen - a male - was found on the horse whereas 3 females, 2 of which were engorged, were found on sheep. During a previous study performed with a horse-baited trap (Fall et al., 2015), no engorged female of this species was found despite a high abundance in light-trap collections in the area (Diarra et al., 2014).

We observed females belonging to the Lasiohelea subgenus to cause major nuisance to the horse and sheep, in particular during the day with pre-sunset peak of activity. No information is available regarding the role of species of this subgenus in virus transmission. In Australia, an undescribed species of day-feeding midge belonging to this subgenus was recently identified as possible vector of Leishmania enrietti complex to the red kangaroo (Macropus 
rufus) (Dougall et al., 2011). Further research is needed to identify this species and its potential role in Orbivirus transmission. However, due to the pattern of AHSV and BTV outbreaks observed worldwide, it was always accepted that night active insects will play a more important role in Orbivirus transmission.

\section{Conclusion}

The eco-epidemiological features of Culicoides midges populations in the Niayes area of Senegal differs from southern Africa, with the predominance of C. oxystoma (vs. C. imicola), the attractiveness of horses to this species, its continuous activity (mostly crepuscular), and the lack of information regarding its vector competence for Orbiviruses, notably for the AHSV. Knowledge is too scarce to allow the development of operational methods for controlling populations of these midges in the field (Carpenter et al., 2008). In particular, further research on the larval ecology and resting behaviour of this species would provide relevant information for developing more efficient control methods. Moreover, similar work should be done in other ecosystems in Senegal where other Culicoides species - particularly those of the Avaritia sub-genus, are more abundant.

\section{Acknowledgments}

This study was funded partly from the EU FP7-HEALTH-2010-single-stage grant 261504 EDENext. This paper is catalogued by the EDENext Steering Committee as EDENext322 (http://www.edenext.eu). The contents of this publication are the sole responsibility of the authors and do not necessarily reflect the views of the European Commission.

\section{References}

Auriault, M. (1977) Contribution à l'étude biologique et écologique de Culicoides grahamii (Austen), 1909, (Diptera: Ceratopogonidae) I. Rythme d'activité des femelles. Cahiers ORSTOM, serie Entomologie médicale et Parasitologie,15, 171-176.

Auriault, M. (1979) Contribution à l'étude biologique et écologique de Culicoides grahamii (Austen) 1909, (Diptera: Ceratopogonidae) V-Rythme d'activité en forêt dense. Cahiers ORSTOM, serie Entomologie médicale et Parasitologie,17, 77-79.

Bakhoum, M., Fall, M., Fall, A., Bellis, G., Gottlieb, Y. \& Labuschagne, K. (2013) First record of Culicoides oxystoma Kieffer and diversity of species within the Schultzei group of Culicoides Latreille (Diptera: Ceratopogonidae) biting midges in Senegal. PLOS ONE,8, 1 - 8. 
Barnard, B. J. H. (1997) Some factors governing the entry of Culicoides spp. (Diptera: Ceratopogonidae) into stables. Onderstepoort Journal of Veterinary Research,64, 227-233.

Bhasin, A., Mordue Luntz, A. J. \& Mordue, W. (2001) Field studies on efficacy of host odour baits for the biting midge Culicoides impunctatus in Scotland. Medical and Veterinary Entomology,15, 147156.

Boorman, J. (1989) Culicoides (Diptera: Ceratopogonidae) of the Arabian peninsula with notes on their medical and veterinary importance. Fauna of Saudi Arabia,10, 160-224.

Boorman, J. \& Dipeolu, O. O. (1979) A taxonomic study of adult Nigerian Culicoides Latreille (Diptera: Ceratopogoaidae) species. Occasional Publications of the Entomological Society of Nigeria,22, 1-121. Carpenter, S., Mellor, P. S. \& Torr, S. J. (2008) Control techniques for Culicoides biting midges and their application in the U.K. and northwestern Palaearctic. Medical and Veterinary Entomology,22, 175-187.

Cornet, M. (1969) Les Culicoides (Diptera: Ceratopogonidae) de l'Ouest Africain (1ere note). Cahiers ORSTOM, serie Entomologie médicale et Parasitologie,7, 341-364.

Cornet, M. \& Brunhes, J. (1994) Révision des espèces de Culicoides apparentées à C. shultzei (Enderleini, 1908) dans la région afro-tropicale (Diptera: Ceratopogonidae). Bulletin de la Société Entomologique de France, 92, 149-164.

Diarra, M., Fall, M., Fall, A., Diop, A., Seck, M., Garros, C., et al.(2014) Seasonal dynamics of Culicoides (Diptera: Ceratopogonidae) biting midges, potential vectors of African horse sickness and bluetongue viruses in the Niayes area of Senegal. Parasites \& Vectors, $7,147$.

Dougall, A. M., Alexander, B., Holt, D. C., Harris, T., Sultan, A. H., Bates, P. A., et al. (2011) Evidence incriminating midges (Diptera: Ceratopogonidae) as potential vectors of Leishmania in Australia. International Journal for Parasitology, 41, 571-579.

Dow, R. P., Reeves, W. C. \& Bellamy, R. E. (1957) Field tests of avian host preference of Culex tarsalis Coq. American Journal of Tropical Medicine and Hygiene, 6, 294-303.

Dyce, A. L. (1969) The recognition of nulliparous and parous Culicoides (Diptera: Ceratopogonidae) without dissection. Journal of the Australian Entomological Society,8, 11-15.

Edman, J. D., Webber, L. A. \& Schmid, A. A. (1974) Effect of host defences on the feeding pattern of Culex nigripalpus when offered a choice of blood sources. Journal of Parasitology,60, 874-883.

El Sinnary, K. A., Muller, R., Atta El Mannan, A. \& Hussein, S. H. (1985) The diurnal activity of Culicoides kingi in northern Sudan. Revue d'Elevage et de Médecine Vétérinaire des Pays Tropicaux, 38, 270-275.

Fall, M., Diarra, M., Fall, A., Balenghien, T., Seck, M., Bouyer, J., et al.(2015) Culicoides (Diptera: Ceratopogonidae) midges, the vectors of African horse sickness virus - a host/vector contact study in the Niayes area of Senegal. Parasites \& Vectors, $8,39$.

Glick, J. I. (1990) Culicoides biting midges (Diptera: Ceratopogonidae) of Kenya. Journal of Medical Entomology, 27, 85-195.

Humphreys, J. G. \& Turner, J. E. C. (1973) Blood-feeding activity of female Culicoides (Diptera: Ceratopogonidae). Journal of Medical Entomology, 10, 79-83.

Itoua, A., Cornet, M., Vattier-Bernard, G. \& Trouillet, J. (1987) The Culicoides (Diptera: Ceratopogonidae) of Central Africa. Cahiers ORSTOM, serie Entomologie médicale et Parasitologie, 127-134.

Kremer, M., Rebholtz-Hirtzel, C. \& Delécolle, J. C. (1975) Description d'une espèce nouvelle C. dubitatus n. sp. (Diptera: Ceratopogonidae) de la région éthiopienne. Cahiers ORSTOM, serie Entomologie médicale et Parasitologie,13 233-236.

Kurogi, H., Akiba, K., Inaba, Y. \& Matumoto, M. (1987) Isolation of Akabane virus from the biting midge Culicoides oxystoma in Japan. Veterinary Microbiology, 15, 243-248.

Lardeux, F., Loayza, P. \& Bouchité, B. C. (2007) Host choice and human blood index of Anopheles pseudopunctipennis in a village of the Andean valleys of Bolivia. Malaria Journal,6, 14.

Meiswinkel, R. (1989) Afrotropical Culicoides: a redescription of C. (Avaritia) imicola Kieffer, 1913 (Diptera: Ceratopogonidae) with description of the closely allied C. (Avaritia) bolitinos sp. Nov. reared 
from the dung of the african buffalo, blue wildebeest and cattle in South Africa. Onderstepoort Journal of Veterinary Research,56, 23-39.

Meiswinkel, R. (1991) Afrotropical Culicoides: C. (Avaritia) miombo sp. nov., a widespread species closely allied to C. (Avaritia) imicola Kieffer, 1913 (Diptera: Ceratopogonidae). Onderstepoort Journal of Veterinary Research,58, 155-170.

Meiswinkel, R., Baylis, M. \& Labuschagne, K. (2000) Stabling and the protection of horses from Culicoides bolitinos (Diptera: Ceratopogonidae), a recently identified vector of African horse sickness. Bulletin of Entomological Research,90, 509-515.

Meiswinkel, R. \& Paweska, J. T. (2003) Evidence for a new field Culicoides vector of African horse sickness in South Africa. Preventive Veterinary Medicine,60, 243-253.

Mellor, P. S., Boorman, J. \& Baylis, M. (2000) Culicoides biting midges: their role as arbovirus vectors. Annual Review of Entomology, 45, 307- 340.

Mellor, P. S. \& Hamblin, C. (2004) African horse sickness. Veterinary Research,35, 445-466.

Mellor, P. S., Osborne, R. \& Jennings, D. M. (1984) Isolation of bluetongue and related viruses from Culicoides spp. in the Sudan. Journal of Hygiene,93, 621-628.

Morag, N., Saroya, Y., Bravermann, Y., Klement, E. \& Gottlieb, Y. (2012) Molecular identification, phylogenetic status and geographic distribution of Culicoides oxystoma (Diptera: Ceratopogonidae) in Israel. PLOS ONE,7, e33610.

Mullens, B. A. (1995) Flight activity and response to carbon-dioxide of Culicoides variipennis sonorensis (Diptera: Ceratopogonidae) in southern California. Journal of Medical Entomology,32, 310-315.

Mushi, E. Z., Isa, J. F. W., Chabo, R. G., Binta, M. G. \& Kapaata, R. W. (1998) Culicoides (Diptera: Ceratopogonidae) associated with horses at Mogoditshane, Gaborone, Botswana. Veterinary Research Communications, 22, 295-297.

Nakagawa, S. \& Schielzeth, H. (2013) A general and simple method for obtaining $R^{2}$ from generalized linear mixed-effects models. Methods in Ecology and Evolution,4, 133-142.

Nelson, R. L. (1965) Carbon dioxide as an attractant for Culicoides. Journal of Economic Entomology, 2, 56-57.

Nicholas, W. M. (1953) The bionomics of Culicoides austeni, vector of Acanthocheilonema perstans in the rain-forest of the British Cameroons, together with notes on $C$. grahamii and other species which may be vectors in the same area. Annals of Tropical Medicine and Parasitology,47, 187-206.

Oem, J. K., Chung, J. Y., Kwon, M. S., Kim, T. K., Lee, T. U. \& Bae, Y. C. (2013) Abundance of biting midge species (Diptera: Ceratopogonidae, Culicoides spp.) on cattle farms in Korea. Journal of Veterinary Science, 14, 91-94.

Prasad, G., Malik, Y. \& Sushila. (1999) Bluetongue: an alarming disease to livestock industry in India. Indian Farming,49, 16-20.

R_Core_Team. (2014) R version 3.1.1: A language and environment for statistical computing. $R$ Foundation for Statistical Computing, Vienna, Austria. ULR: http://www.R-project.org/.

Raich, T., Jacobson, M., Holbrook, F., Babion, R., Blair, C. \& Beaty, B. J. (1997) Culicoides variipennis (Diptera: Ceratopogonidae) host selection in Colorado. Journal of Medical Entomology, 34, 247-249.

Rawlings, P., Pro, M. J., Pena, I. \& Ortega, M. D. C. (1997) Spatial and seasonal distribution of Culicoides imicola in Iberia in relation to the transmission of African horse sickness virus. Medical and Veterinary Entomology, 11, 49-57.

Satheesha, S. P., Udupa, K. G., Appannavar, M. M. \& Labuschagne, K. (2014) A study on Culicoides midges associated with buffaloes. Buffalo Bulletin, 33, 400-406.

Scheffer, E. G., Venter, G. J., Labuschagne, K., Page, P. C., Mullens, B. A., MacLachlan, N. J., et al.(2012) Comparison of two trapping methods for Culicoides biting midges and determination of African horse sickness virus prevalence in midge populations at Onderstepoort, South Africa. Veterinary Parasitology, 185, 265-273.

Takken, W. \& Verhulst, N. O. (2013) Host preferences of blood-feeding mosquitoes. Annual Review of Entomology, 58, 433-453. 
Tanner, G. D. \& Turner, J. E. C. (1974) Vertical activities and host preferences of several Culicoides species in a southwestern Virginia Forest. Mosquito News,34, 66-70.

Vattier-Bernard, G., Itoua, A., Trouillet, J. \& Lallemant, M. (1986) Les Ceratopogonidae (Diptera) du Mayombé Congolais. 1. Rythme d'activité journalier des femelles de Culicoides grahamii Austen, 1909. Annales de Parasitologie Humaine et Comparée, 61, 367-377.

Venter, G. J., Graham, S. D. \& Hamblin, C. (2000) African horse sickness epidemiology: vector competence of south african Culicoides species for virus serotypes 3, 5 and 8. Medical and Veterinary Entomology, 14, 245-250.

Venter, G. J., Groenewald, D. M., Paweska, J. T., Venter, E. H. \& Howell, P. G. (1999) Vector competence of selected South African Culicoides species for the Bryanston serotype of equine encephalosis virus. Medical and Veterinary Entomology,13, 393-400.

Venter, G. J., Meiswinkel, R., Nevill, E. M. \& Edwards, M. (1996) Culicoides (Diptera: Ceratopogonidae) associated with livestock in the Onderstepoort area, Gauteng, South Africa as determined by light trap collections. Onderstepoort Journal of Veterinary Research, 63, 315-325.

Viennet, E., Garros, C., Gardes, L., Rakotoarivony, I., Allene, X., Lancelot, R., et al. (2012) Host preferences of Palaearctic Culicoides biting midges: implications for transmission of orbiviruses. Medical and Veterinary Entomology, 1-12.

Walker, A. R. (1977) Seasonal fluctuations of Culicoides species (Diptera: Ceratopogonidae) in Kenya. Bulletin of Entomological Research,67, 217-233.

Wirth, W. W. \& Marston, N. (1968) A method for mounting small insects on microscope slides in canada balsam. Annals of the Entomological Society of America,61, 783-784.

Yanase, T., Kato, T., Kubo, T., Yoshida, K., Ohashi, S., Yamakawa, M., et al. (2005) Isolation of bovine arboviruses from Culicoides biting midges (Diptera: Ceratopogonidae) in southern Japan: 1985-2002. Journal of Medical Entomology,42, 63-67. 